\title{
SCB THERMITE IGNITER STUDIES
}

\author{
R. W. Bickes, Jr., and D. E. Wackerbarth \\ Sandia National Laboratories \\ Albuquerque, New Mexico \\ Jonathan $\mathrm{H}$. Mohler \\ Energetic Materials Associates, Inc. \\ Vero Beach, FL 32968
}

\section{MASTER}

\section{$\underline{\text { Abstract }}$}

We report on recent studies comparing the ignition threshold of temperature cycled, SCB thermite devices with units that were not submitted to temperature cycling. Aluminum/copper-oxide thermite was pressed into units at two densities, $45 \%$ of theoretical maximum density (TMD) or $47 \%$ of TMD. Half of each of the density sets underwent three thermal cycles; each cycle consisted of 2 hours at $74 \mathrm{C}$ and 2 hours at $-54 \mathrm{C}$, with a 5 minute maximum transfer time between temperatures. The temperature cycled units were brought to ambient temperature before the threshold testing. Both the density and the thermal cycling affected the all-fire voltage. Using a $5.34 \mu \mathrm{F}$ CDU (capacitor discharge unit) firing set, the all-fire voltage for the units that were not temperature cycled increased with density from $32.99 \vee(45 \% \mathrm{TMD})$ to $39.32 \vee(47 \% \mathrm{TMD})$. The all-fire voltages for the thermally cycled units were $34.42 \mathrm{~V}(45 \% \mathrm{TMD})$ and $58.1 \mathrm{~V}$ (47\% TMD). We also report on no-fire levels at ambient temperature for two component designs; the 5 minute no-fire levels were greater than 1.2 A. Units were also subjected to tests in which $1 \mathrm{~W}$ of RF power was injected into the bridges at $10 \mathrm{MHz}$ for 5 minutes. The units survived and fired normally afterwards. Finally, units were subjected to pin-to-pin electrostatic discharge (ESD) tests. None of the units fired upon application of the ESD pulse, and all of the tested units fired normally afterwards.

\section{Introduction}

Ignition difficulties exhibited by many thermite compositions result from their high thermal conductivity. In particular, hot-wire ignition is especially affected because the temperature rise of the wire is slow and energy transfer from the wire to the thermite is controlled by conduction.

This paper is declared a work of the U.S. Government and is not subject to copyright protection in the United States.
Consequently a large mass of material outside of the critical ignition zone is unnecessarily heated before achieving ignition, which increases the amount of energy required from the firing set.

Semiconductor bridges, SCBs, on the other hand, form a plasma discharge in microseconds which rapidly transfers energy via a convective process to the thermite. This produces a high power density in the ignition zone with less energy loss to surrounding materials. Consequently, by using an SCB, thermite compositions can be exploited for pyrotechnic igniters without paying an ignition energy penalty. Through proper choice of charge holder and component materials, electrical ignition energies that rival more traditional pyrotechnic igniter compositions can be achieved.

\section{Semiconductor Bridge, SCB}

Sandia's semiconductor bridge, SCB, has three forms that were patented in $1987^{1}$ and $1990 .^{2}$ Devices utilizing the 1987 patent have been incorporated into Sandia systems for the Department of Energy ${ }^{3,4}$ (DOE) for the Department of Defense ${ }^{5}$ (DoD), and for commercial systems. ${ }^{6}$

The device described in the 1987 patent is shown in Fig. 1. It consists of a small doped polysilicon (or silicon) volume formed on a silicon (or sapphire) substrate. The length of the bridge is determined by the spacing of the aluminum lands seen in the figure. The lands provide a low ohmic contact to the underlying doped layer. Wires ultrasonically bonded to the lands and the electrical feedthroughs on the explosive header permit a current pulse to flow from land-to-land through the bridge; the ultrasonic process produces very strong bonds and is a cost effective procedure. The doped layer is typically $2 \mu \mathrm{m}$ thick. Bridge resistance at room temperature is $1 \Omega$; however, 


\section{DISCLAIMER}

This report was prepared as an account of work sponsored by an agency of the United States Government. Neither the United States Government nor any agency thereof, nor any of their employees, make any warranty, express or implied, or assumes any legal liability or responsibility for the accuracy, completeness, or usefulness of any information, apparatus, product, or process disclosed, or represents that its use would not infringe privately owned rights. Reference herein to any specific commercial product, process, or service by trade name, trademark, manufacturer, or otherwise does not necessarily constitute or imply its endorsement, recommendation, or favoring by the United States Government or any agency thereof. The views and opinions of authors expressed herein do not necessarily state or reflect those of the United States Government or any agency thereof. 


\section{DISCLAMMER}

Portions of this document may be illegible in electronic image products. Images are produced from the best available original document. 
the bridge dimensions can be easily altered to produce other resistances or shapes for specific applications.

A current pulse through the SCB causes it to burst into a bright plasma discharge that heats the exoergic material pressed against the bridge by a rapid and efficient convective process. ${ }^{7}$ Consequently, SCB devices operate at input energies typically less than $5 \mathrm{~mJ}$ (and as low as 30 $\mu \mathrm{J})$. But the SCB devices function very quickly producing an explosive output in less than $60 \mu \mathrm{s}$ for pyrotechnic devices (where $60 \mu \mathrm{s}$ is the interval from the firing pulse to the usable explosive output of the device).

Despite the low energy for ignition, the substrate provides a reliable heat sink for excellent no-fire levels. Because the physics of SCB operation is so very much different than for hot wires, SCB devices have both low input energy requirements and high no-fire levels. ${ }^{8}$ In addition, and as described later, the devices are ESD (electrostatic discharge) and $\mathrm{RF}$ (radio frequency) tolerant

\section{Ignition Studies}

This section is a very brief review of ignition studies $^{9}$ that contributed to the design of the components tested in this paper. For those studies type 50B1 SCB die were mounted on standard TO-46 transistor headers; bridge dimension were $90 \mu \mathrm{m}$ long, $270 \mu \mathrm{m}$ wide and 2 $\mu \mathrm{m}$ thick. For some of the tests the charge holders were brass cylinders (see Fig. 2) and for the other tests the charge holders (see Fig. 3) were assembled with a G10 charge holder (G10 is a nonelectrically conductive, fiber-glass-epoxy composite).

The CDU firing set for these studies consisted of a charge capacitor switched by an SCR into a series circuit with the SCB and current viewing resistor (see Fig. 4). We used ceramic capacitors from AVX Corporation; ${ }^{10}$ capacitances ranged from $1 \mu \mathrm{F}$ to $40 \mu \mathrm{F}$. The SCB voltage and current waveforms were captured from digitizers and analyzed to obtain the energy in the firing pulse to the SCB.

Our experiments measured the threshold for ignition as a function of the CDU capacitance at a charge voltage of $50 \mathrm{~V}$ and with the capacitor and the device both at $0^{\circ} \mathrm{F}$. For the brass charge holder the mean all-fire capacitance was $30.1 \mu \mathrm{F} \pm$ $0.2 \mu \mathrm{F}$. For the G10 units, we obtained a mean capacitance of $2.08 \mu \mathrm{F} \pm 0.45 \mu \mathrm{F}$.

Clearly the mean all-fire thresholds were significantly influenced by the type of charge holder sleeve. The all-fire capacitance for the G10 units was approximately one-tenth that of the brass units. We believe that the reduction in threshold capacitance may be due to thermal losses at the metal charge holder or an influence on the SCB plasma by the ground plane provided by the brass cylinder. These results lead to the G10 designs for the devices tested in this paper.

\section{Threshold Studies}

Energetic Materials Associates (EMA) built the devices for testing at Sandia National Laboratories (SNL). A schematic sketch of a device is shown in Fig. 5. Forty devices were loaded with $\mathrm{Al} / \mathrm{CuO}$ thermite and pressed to densities of $45 \%$ of TMD $\left(2.3 \mathrm{~g} / \mathrm{cm}^{3} 175 \mathrm{mg}\right.$ load) or $47 \%$ of TMD $(2.4$ $\mathrm{g} / \mathrm{cm}^{3} 183 \mathrm{mg}$ load). We used spherical, atomized aluminum, ${ }^{11}$ and 13600 copper oxide which was commercially processed by air oxidation of fine particle copper. ${ }^{12}$ Ten of the $45 \%$ TMD and ten of the $47 \%$ TMD devices underwent 3 thermal cycles; each cycle consisted of 2 hours at $74 \mathrm{C}$ and 2 hours at $-54 \mathrm{C}$ with a 5 minute maximum transfer time between temperatures. The units were brought to ambient temperature 12 hours before the onset of testing.

Baseline thresholds as a function of charge capacitor voltage were measured for ten of the $45 \%$ TMD units and ten of the $47 \%$ TMD units that were not subjected to thermal environments. Then we carried out the same measurements for the thermally cycled units. All of the units were tested at ambient. We used the Neyer Sensit ${ }^{13}$ program to determine the threshold voltage levels and the ASENT program to analyze the data.

Table I. summarizes the results of our experiments. Clearly density affects the all-fire voltages. For the devices that did not undergo thermal cycling, the mean all-fire voltage increased from $33.0 \mathrm{~V}$ for the $45 \%$ TMD devices to $39.3 \mathrm{~V}$ for the $47 \%$ devices. Similarly, for the thermally cycled units the increase

Page -2-

American Institute of Aeronautics and Astronautics 
was from $34.4 \mathrm{~V}$ to $58.1 \mathrm{~V}$ for the $45 \%$ and $47 \%$ TMD units, respectively. But the major effect was temperature shock. For the higher density material at $47 \% \mathrm{TMD}$, the threshold increased from $39.3 \mathrm{~V}$ to $58.1 \mathrm{~V}$.

\section{No-Fire Studies}

The results of the previous tests revealed that reliable ignition required a low density against the SCB. EMA developed a reverse loading procedure in which units were assembled with the first load consolidated into the top of the charge holder at either $45 \%$ TMD or $47 \%$ TMD. The second load was pressed to $42 \%$ TMD, and then the SCB header was inserted into the charge holder such that the chip was against the second, low density, thermite load. Two units were tested, the first was as shown in Fig. 5, and the second unit with a steel shell is seen in Fig. 6 .

The no-fire current was applied to the devices for 5 minutes; the bridge resistance before and after the test was recorded. The units were then tested using the firing set shown in Fig. 7. This CDU firing set was designed to operate from a $9 \mathrm{~V}$ battery; it contained a solid state 5-to-1 voltage converter that increased the charge voltage on the $9.57 \mu \mathrm{F}$ to $45 \mathrm{~V}$.

The results of our tests are summarized in Table II. The no-fire level for both units exceeded $1.0 \mathrm{~A}$ as units tested at 1.1 and 1.2 A did not fire upon a 5 minute application of the d.c. current. In addition, all of the units functioned properly after the application of the no-fire pulse. A full statistical study is needed to provide precise definitions of the no-fire levels for these devices.

\section{ESD \& RF Studies}

The Sandia Standard Man ESD test places the unit under test in series with a $500 \Omega$ resistor and a 600 pF capacitor. The capacitor is charged to $20 \mathrm{kV}$ and then discharged through the unit and $500 \Omega$ resistor using a fast rise-time switch. We tested units at 20,15 and $10 \mathrm{kV}$. The applied pulses were pin-to-pin; that is, the current pulse was through the SCB as opposed to a pin-to-case test. We also submitted 2 units to the standard DoD ESD test. For the DoD tests the units are in series with a
$5000 \Omega$ resistor and a $500 \mathrm{pF}$ capacitor charged to $25 \mathrm{kV}$. The results are summarized in Table III. None of the units fired when subjected to the ESD pulses. However the Standard Man test at 20 and $15 \mathrm{kV}$ did damage the bridge as indicated by the change in resistance.

After the ESD testing, all of the units were tested using the firing set in Fig. 7 charged to $45 \mathrm{~V}$. All but one of the units functioned properly. However, the current waveform for the no-fire indicated that the bridge was not in normal contact with the thermite (perhaps due to an assembly problem); the unit will be dissected and examined to determine the cause of the no fire.

Two of the steel units were injected with 1 Watt of RF power at $10 \mathrm{MHz}$ input frequency for 5 minutes. The resistances of the units increased slightly after the RF injection but none of the units functioned (see Table IV). A third unit was subjected to 2, 3, ..., and 8 Watt injections, each 5 minutes long; again the unit did not fire. However at 8 Watt the bridge was damaged or the thermite began to react producing a unit resistance of only $0.5 \Omega$.

The two units tested at 1 Watt were fired using the $9.57 \mu \mathrm{F}, 45 \mathrm{~V}$ firing set and functioned properly (Table IV). The third unit will be opened and examined.

\section{Summary and Conclusions}

Clearly density affects the all-fire voltages. For the devices that did not undergo thermal shock, the mean all-fire increased $19 \%$ when the TMD increased from $45 \%$ to $47 \%$. Thermal cycling of the $45 \%$ TMD devices increased the threshold only $4 \%$, but the increase was $48 \%$ for the $47 \%$ "TMD thermite. The data suggest that units should be processed at the lower density.

Like other SCB devices, the no-fire levels were greater than the common $1 \mathrm{~A} / 1 \mathrm{~W}$ criterion. A full statistical test should be made to verify our results, but we feel confident that the data here accurately characterize the excellent no-fire capabilities of these devices. Finally, all of the units survived ESD and RF injection and all but one of the units later functioned properly when fired using the $9.57 \mu F / 45 \vee$ firing set. 


\section{Acknowledgments}

This work was supported by the United States Department of Energy under Contract DE-AC0494AL85000. Sandia is a multiprogram laboratory operated by Sandia Corporation, a Lockheed Martin Company, for the United States Department of Energy. This research was sponsored by the Small Business Initiative at Sandia National Labs.

\section{$\underline{\text { References }}$}

${ }^{1}$ R. W. Bickes, Jr., A. C. Schwarz, "Semiconductor Bridge (SCB) Initiator," U.S. Patent 4,708,060 (Nov. 1987).

${ }^{2}$ D. A. Benson, R. W. Bickes, Jr., R. W. Blewer, "A Tungsten Bridge for the Low Energy Ignition of Explosive and Energetic Materials," U.S. Patent 4,976,200 (Dec. 1990).

${ }^{3}$ R. W. Bickes, Jr., M. C. Grubelich, S. M. Harris, J. A. Merson, J. H. Weinlein, "An Overview of Semiconductor Bridge, SCB, Applications at Sandia National Laboratories, $31^{\text {st }}$ AIAA/ASME/SAE/ASEE Joint Propulsion Conference and Exhibit, American Institute of Aeronautics and Astronautics, (May 1995), SAND 95-0968C.

${ }^{4}$ W. W. Tarbell, D. H. Sanchez, M. L. Oestreich and J. W. Prentice, "Development and Production of Two Explosive Components Using SCB Technology, ibid..

${ }^{5}$ D. Nowakowski, "Using Semiconductor Bridge Technology in a Life Support Application, 1996 SAFE Symposium, Reno, NV (Nov. 1996).

${ }^{6} \mathrm{~J}$. Motley and J. Barker, "Unique Electrical Detonator Enhances Safety in Explosive Operations: Case Histories, SPE Annual Technical Conference and Exhibition, Denver, CO (Oct. 6-9, 1996)

${ }^{7}$ D. A. Benson, M. E. Larsen, A. M. Renlund, W. M. Trott, and R. W. Bickes, Jr., "Semiconductor Bridge (SCB): A Plasma Generator for the Ignition of Explosives," Journ. Appl. Phys. 62(5), 16221632, (Sept. 1987).
${ }^{8}$ R. W. Bickes, Jr., S. L. Schlobohm and D. W. Ewick, "Semiconductor bridge (SCB) Studies: I. Comparison of SCB and Hot-Wire Pyrotechnic Actuators," $13^{\text {th }}$ International Pyrotechnics Seminar, p. 69, Grand Junction, Colorado (July 1988)

${ }^{9}$ R. W. Bickes, Jr., M. C. Grubelch, D. E. Wackerbarth and J. H. Mohler, "A Low-Ignition Energy, SCB, Thermite Igniter," Twenty-Second International Pyrotechnics Seminar, Fort Collins, July 15-19, 1996, SAND96-0480C.

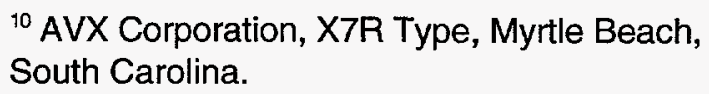

${ }^{11}$ Valimet Inc., Stockton, California, H-3 material with a mean diameter of $3.8 \mu \mathrm{m}$.

${ }^{12}$ American Chemet Corp., Deerfield, Illinois, type 13600 copper oxide is prepared by air oxidation of fine copper particles.

${ }^{13}$ B. T. Neyer, "More Efficient Sensitivity Testing," EG\&G Mound Applied Technologies, MLM-3609, (October 20, 1989). 


\section{TABLES AND FIGURES}

\section{TABLE I: THRESHOLD DATA SUMMARY}

$\begin{array}{cccccc}\text { Temp. } & \begin{array}{c}\text { Density } \\ \text { (\% TMD) }\end{array} & \begin{array}{c}\text { Mean } \\ \text { Shock }\end{array} & \begin{array}{c}\text { Sigma } \\ \text { (V) }\end{array} & \begin{array}{c}\text { L5\% Confidence Limits at } 0.999 \\ \text { Lower Limit }\end{array} & \begin{array}{c}\text { Upper Limit } \\ \text { (V) }\end{array} \\ \text { No } & 45 \% & 33.0 & 1.0 & & \\ \text { No } & 47 \% & 39.3 & 0.8 & 32.3 & 39.9 \\ \text { Yes } & 45 \% & 34.4 & 1.7 & 33.11 & 44.5 \\ \text { Yes } & 47 \% & 58.0 & 16.3 & \ldots & 46.3 \\ & & & & & \ldots\end{array}$

TABLE II: NO-FIRE STUDIES

$\begin{array}{ccccc}\begin{array}{c}\text { No-Fire } \\ \text { Current } \\ (\mathrm{A})\end{array} & \begin{array}{c}\text { SCB Resistance } \\ \text { Before Test } \\ (\Omega)\end{array} & \begin{array}{c}\text { SCB Resistance } \\ \text { After Test } \\ (\Omega)\end{array} & \begin{array}{c}\text { Device } \\ \text { Type }\end{array} & \begin{array}{c}\text { Go } \\ \text { NoGo } \\ (\mathrm{X} / \mathrm{O})\end{array} \\ \begin{array}{ccccc} \\ 1.0\end{array} & 1.037 & 1.031 & \mathrm{G} 10 & \mathrm{X} \\ 1.0 & 1.000 & 0.992 & \mathrm{G} 10 & \mathrm{X} \\ 1.1 & 1.011 & 0.999 & \mathrm{G} 10 & \mathrm{X} \\ 1.2 & 1.018 & 0.949 & \mathrm{G} 10 & (\mathrm{a}) \\ 1.0 & 1.060 & 1.055 & \text { Steel } & \mathrm{X} \\ 1.0 & 1.048 & 1.086 & \text { Steel } & \mathrm{X} \\ 1.1 & 0.998 & 0.998 & \text { Steel } & \mathrm{X} \\ 1.2 & 1.065 & 2.440 & \text { Steel } & \mathrm{X}\end{array}$

(a) The unit was damaged when the connectors were removed after the no-fire test preventing the all-fire test.

TABLE III: ESD TESTS

$\begin{array}{ccccc}\text { Type } & \text { Voltage } & \begin{array}{c}\text { Resistance } \\ \text { before test } \\ (\Omega)\end{array} & \begin{array}{c}\text { Resistance } \\ \text { after test } \\ (\Omega)\end{array} & \begin{array}{c}\text { Function } \\ \text { Go/NoGo } \\ (\mathrm{X} / O)\end{array} \\ \text { G10 } & (\mathrm{kV}) & 1.018 & 9.54 & \mathrm{X} \\ \mathrm{G} 10 & 20 & 1.001 & 10.91 & \mathrm{X} \\ \mathrm{G} 10 & 20 & 1.008 & 2.089 & \mathrm{X} \\ \text { G10 } & 15 & 1.007 & 1.010 & \mathrm{X} \\ \text { Steel } & 10 & 1.012 & 7.396 & \mathrm{X} \\ \text { Steel } & 20 & 1.049 & 4.621 & \mathrm{X} \\ \text { Steel } & 15 & 1.015 & 1.642 & \mathrm{X} \\ \text { Steel } & 10 & 1.026 & 1.016 & \mathrm{O}\end{array}$

Page -5-

American Institute of Aeronautics and Astronautics 
TABLE IV. RF TESTS

$\begin{array}{ccccc}\text { Type } & \begin{array}{c}\text { RF Power } \\ (W)\end{array} & \begin{array}{c}\text { Resistance } \\ \text { before Test } \\ (\Omega)\end{array} & \begin{array}{c}\text { Resistance } \\ \text { after Test } \\ (\Omega)\end{array} & \begin{array}{c}\text { Function } \\ \text { Go/NoGo } \\ (\text { X/O) }\end{array} \\ \text { Steel } & 1 & 1.205 & 1.255 & \mathrm{X} \\ \text { Steel } & 1 & 1.150 & 1.198 & \mathrm{X} \\ \text { Steel } & 2 & 1.322 & 1.308 & \\ \text { (repeat) } & 3 & 1.308 & 1.378 & \\ \text { (repeat) } & 4 & 1.378 & 1.346 & \\ \text { (repeat) } & 5 & 1.346 & 1.335 & \\ \text { (repeat) } & 6 & 1.335 & 1.316 & \\ \text { (repeat) } & 7 & 1.316 & 1.305 & \\ \text { (repeat) } & 8 & 1.305 & 0.5 & \end{array}$

${ }^{a}$ Repeat indicates the unit first tested at $2 \mathrm{~W}$ was then re-tested at $3,4, \ldots, 8 \mathrm{~W}$.

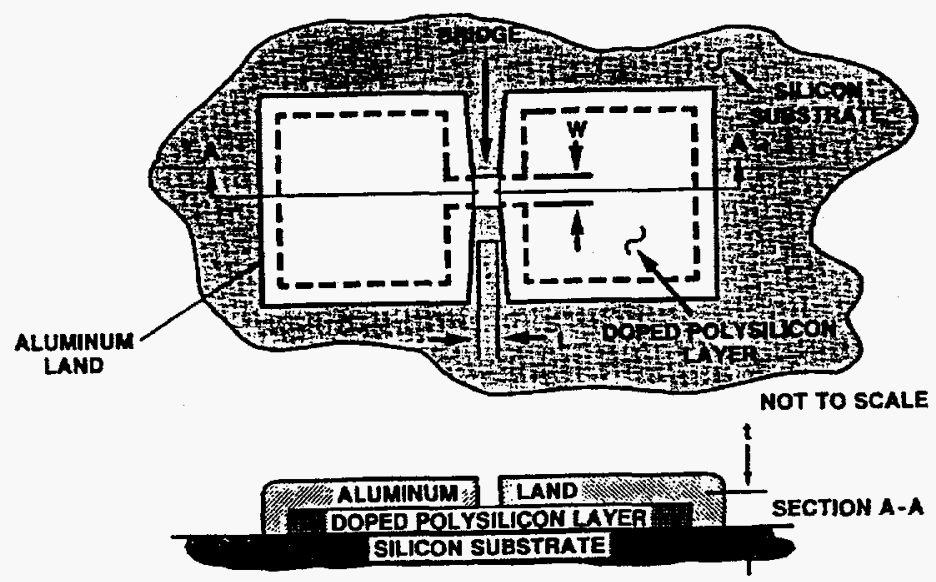

Figure 1. Simplified sketch of a semiconductor bridge (SCB). The bridge is formed out of the heavily doped polysilicon layer enclosed by the dashed lines. The bridge dimensions are $270 \mu \mathrm{m}$ wide $(W)$ by 90 $\mu \mathrm{m}$ long $(L)$ by $2 \mu \mathrm{m}$ thick $(t)$. Electrical leads are attached to the aluminum lands, permitting an applied current pulse to flow from land-to-land through the bridge.

Page -6-

American Institute of Aeronautics and Astronautics 


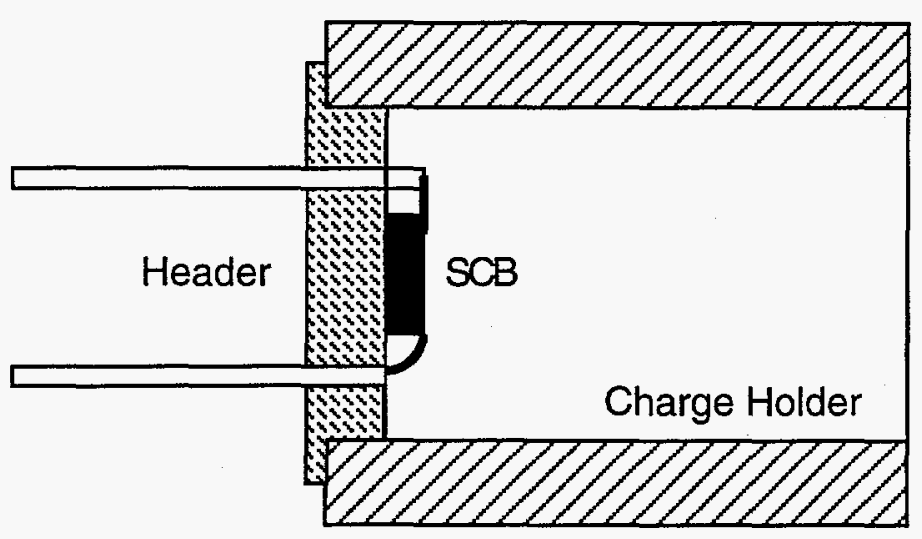

Figure 2. TO-46 transistor base with a brass charge holder. The internal diameter of the charge holder is $0.150^{\prime \prime}(3.8 \mathrm{MM})$ and the internal length is $0.270^{\prime \prime}(6.9 \mathrm{~mm})$. The outside diameter of the charge holder is $0.25^{\prime \prime}(6.4 \mathrm{~mm})$.

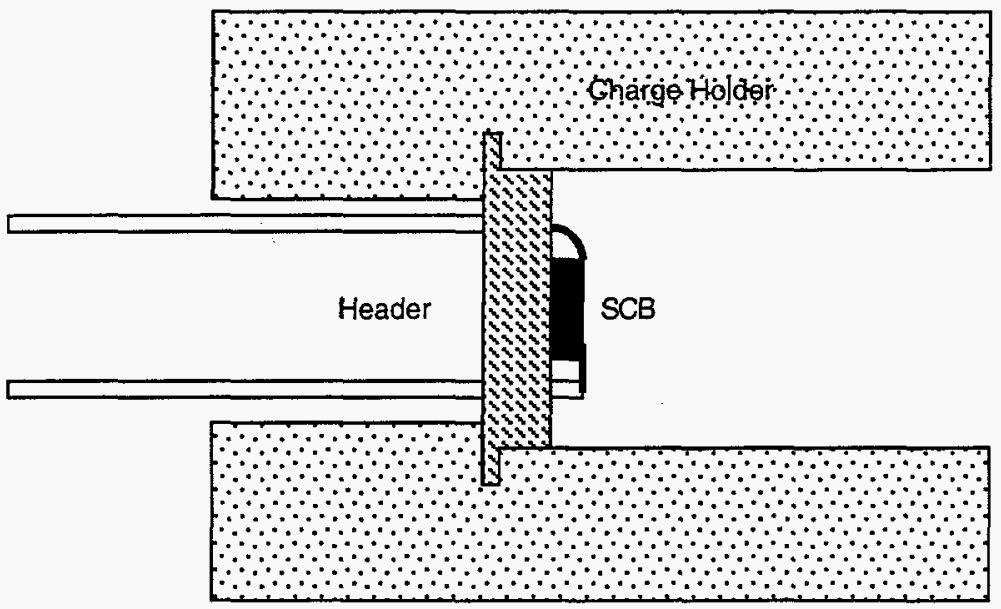

Figure 3. G10 charge holder. The internal diameter is $0.15^{\prime \prime}(3.8 \mathrm{~mm})$ and the length is $0.36^{\prime \prime}(9.1 \mathrm{~mm})$.

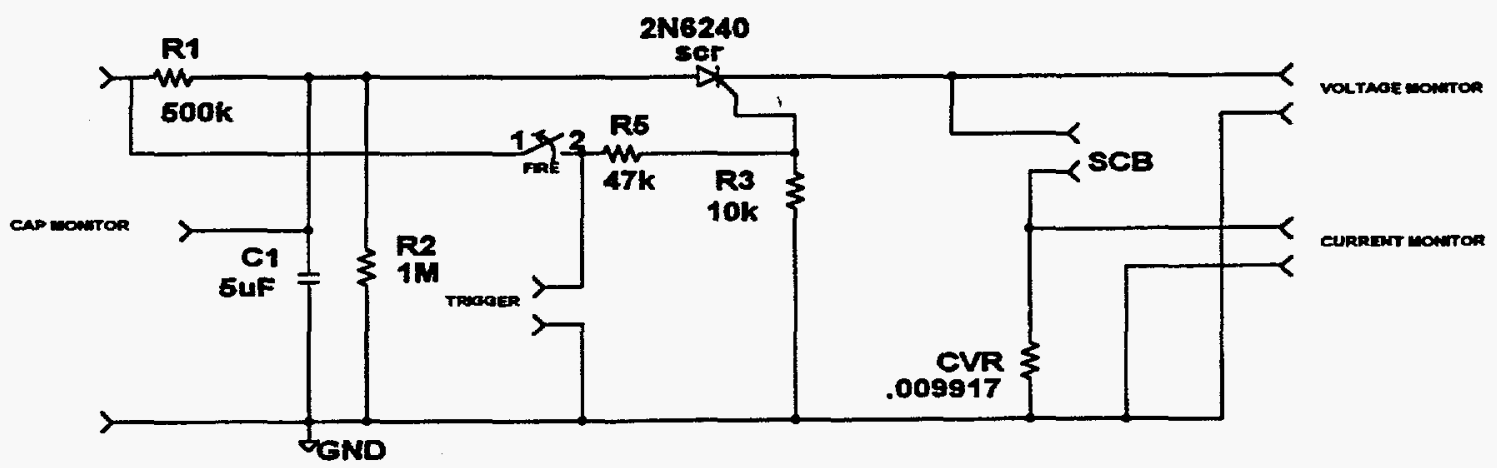

Figure 4. CDU firing set. $C 1$ is the discharge capacitor and is $5 \mu \mathrm{F}$ in this illustration. Current through the bridge is monitored with the current viewing resistor (CVR). A $5 \mathrm{~V}, 10 \mu \mathrm{s}$ trigger fires the switch which can be an SCR as shown or an FET. 


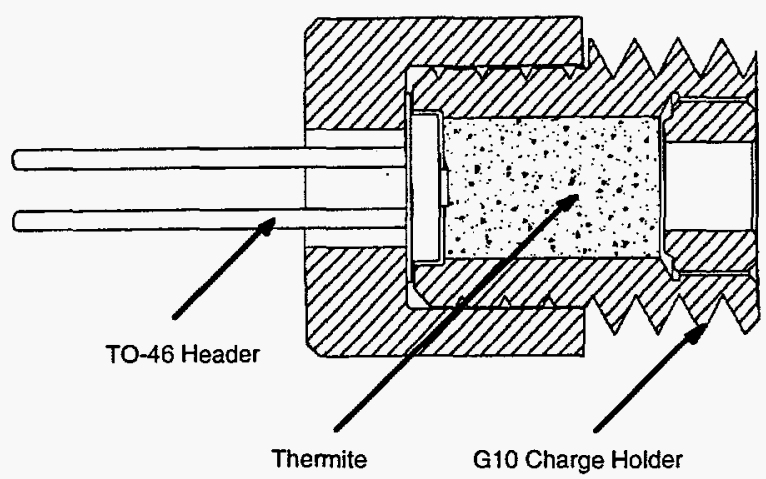

Figure 5. Cross section of the EMA G10 device. The inside diameter of the charge holder was $0.150 . "$

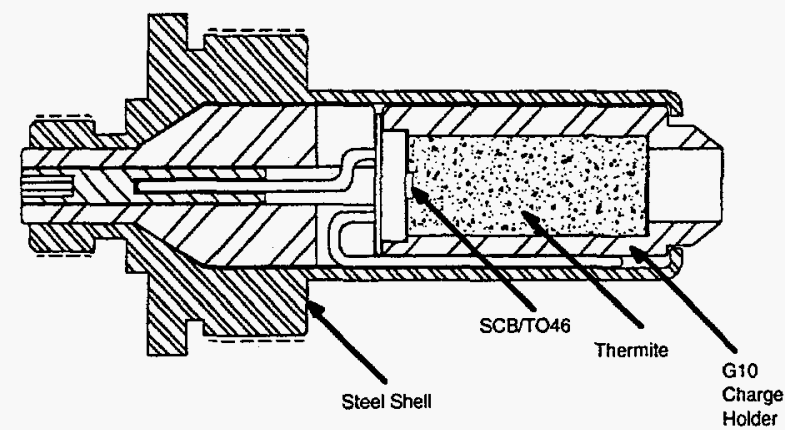

Figure 6. Cross section of the EMA device with a steel shell. The inside diameter of the charge holder was 0.147 , "and the column length was 0.374 ." The unit was reversed loaded-211.8 mg of thermite at $45 \%$ TMD was pressed into the charge holder followed by a second load of $23.7 \mathrm{mg}$ at $42 \%$ TMD. The charge holder with the SCB were then fitted into the charge holder such the second low density load was against the SCB.

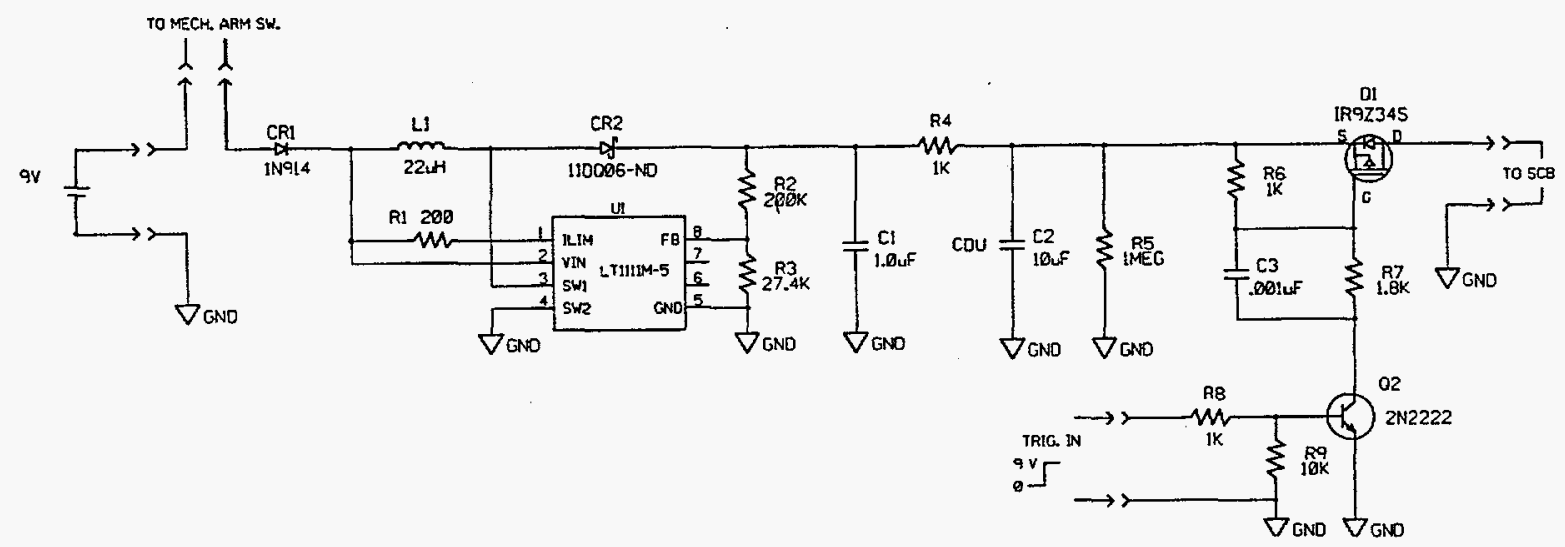

Figure 7. Miniature CDU firing set with a 5-to-1 solid state voltage converter. 